\title{
Recurrent Thyrotoxicosis after Subtotal Thyroidectomy
}

\author{
ANTHONY J. HEDLEY, IAIN P. ROSS, J. SWANSON BECK, DAVID DONALD, \\ F. ALBERT-RECHT, W. MICHIE, JAMES CROOKS
}

British Medical fournal, 1971, 4, 258-261

\section{Summary}

A study of patients with recurrent thyrotoxicosis after subtotal thyroidectomy has shown that the operation has a profound effect on the natural history of Graves's disease. It is followed by pronounced changes in the immunological features of the disease, with a fall in the prevalence of serum thyroid autoantibodies, including the long-acting thyroid stimulator. Thyroid suppression returns to normal in $70 \%$ of patients. The treatment produces two populations of patients. In the larger group there is a permanent remission of the disease process. In the smaller group the disease process persists and, consequently, recurrent hyperthyroidism may develop. The mechanism of the change in the larger group of patients probably has an immunological basis.

\section{Introduction}

The prevalence of recurrent hyperthyroidism after subtotal thyroidectomy for Graves's disease varies considerably in different centres, but it is invariably less than $30 \%$, even when a large remnant of thyroid tissue is left (Table I). There is

TABLE I-Prevalence of Recurrent Hyperthyroidism after Subtotal Thyroidectomy for Graves's Disease

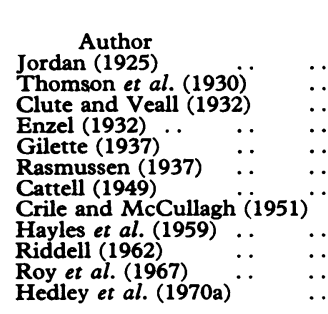

Prevalence of Recurrent Hyperthyroidism (\%) Crile and McCullagh $\ddot{\text { (1951) }}$ Rayles et al. (1959) Roy et al. (1967) Hedley et al. (1970a)

erthyroidism $(\%)$
6.7
19.5
6.2
27.9
6.5
20.7
2.4
15.0
17.9
3.3
11.0
6.0

evidence that radical resection results in a higher incidence of postoperative hypothyroidism, but does not prevent recurrence of hyperthyroidism in a small group of patients; furthermore, hyperthyroidism may recur despite multiple thyroidectomies (McLarty et al., 1969; Hedley et al., 1970a). These findings suggested that in some patients thyrotoxicosis is refractory to surgical treatment, and that in these patients the response to subtotal thyroidectomy is fundamentally different from that of most patients who remain euthyroid or become hypothyroid.

University of Aberdeen and Aberdeen Royal Infirmary

ANTHONY J. HEDLEY, M.B., Research Fellow, Department of Therapeutics and Pharmacology (Present appointment; Medical Registrar, Therapeutics Unit, Maryfield Hospital, Dundee)

IAIN P. ROSS, PH.D., Research Assistant, Department of Therapeutics and Pharmacology (Present appointment: Clinical Biochemist, Western General Hospital, Edinburgh)

J. SWANSON BECK, M.D., F.R.C.P.(GLASG., ED.), Senior Lecturer in Pathology

DAVID DONALD, M.B., Lecturer in Pathology

F. ALBERT-RECHT, M.B., Senior Lecturer in Chemical Pathology

F. ALBERT-RECHT, M.B., Senior Lecturer in Chem
W. MICHIE, M.B., F.R.C.S.ED., Consultant Surgeon

JAMES CROOKS, M.D., F.R.C.P., Reader in Therapeutics (Present appointment: Professor of Pharmacology and Therapeutics, University of Dundee)
The long-acting thyroid stimulator (L.A.T.S.) is a humoral $\frac{\bar{O}}{\bar{D}}$ factor present in the blood of certain patients with Graves's $\frac{\pi}{\sigma}$ disease; it is generally accepted that this is an important factor $\Omega$ in the causation of hyperthyroidism in these patients rather $\%$ than an epiphenomenon (Carneiro et al., 1966). In the present $\overrightarrow{0}$ study we have attempted to determine whether patients who develop recurrent hyperthyroidism after subtotal thyroidectomy $\vec{\omega}$ have persistent production of L.A.T.S. or whether they suffer $\frac{O}{O}$ from a basically different disease. The short-term and long-term effects of subtotal thyroidectomy on the suppressibility of ${ }^{132}$ I uptake of the thyroid gland by triiodothyronine ( $T-3$ of suppression test) and the prevalance of thyroid autoantibodies in the serum have also been studied.

\section{Methods and Patients}

Assay of L.A.T.S.-The L.A.T.S. activity in serum samples $\frac{0}{0}$ was estimated by a modified McKenzie (1958) assay. The "L.A.T.S. response" was considered positive when the mean $\vec{\theta}$ nine-hour mouse blood radioactivity was $\geqslant 300 \%$ of the baseline, and greater than that at three hours; the justification for adhering to this definition of the L.A.T.S. response has been discussed previously (Hedley et al., 1970b). The mean saline response in a large number of assays carried out over a three-year period was $94.8 \pm 3.6 \%$ at three hours (133 mice) and $94.7 \pm 3.8 \%$ at nine hours (160 mice).

Fractionation and Concentration of IgG from Patients' Sera.The IgG fraction was separated with DEAE-Sephadex (A50) in a batch method (Baumstark et al., 1964; Perper et al., 1967). The mean initial serum sample volume was about $55 \mathrm{ml}$; in each case the eluate was concentrated by ultrafiltration under high-pressure nitrogen (Albert-Recht and Stewart, 1961) and reduced to a volume of 3 to $6 \mathrm{ml}$. The immunochemical purity of this fraction was assessed by immunoelectrophoresis (Scheidegger, 1955) against anti-whole-human serum and anti-human IgG antisera (Burroughs Wellcome; Hoechst Pharmaceuticals). The concentration of IgG fractions was assayed by a radial immunodiffusion technique (Fahey and McKelvey, 1965). The efficacy of the fractionation and concentration method was assessed in experiments on 10 potent L.A.T.S. sera and 3 L.A.T.S.-rich serum pools. The recovery of L.A.T.S. activity was estimated from the slopes of the dose response lines in the assay:

$\frac{\text { mean slope of IgG concentrate }}{\text { mean slope of whole serum }}=\%$ recovery of L.A.T.S. The mean recovery of L.A.T.S. was $33.4 \%$ compared with mean recovery of IgG of $34.6 \%$ in these samples.

$T-3$ Suppression Tests.-Before subtotal thyroidectomy and during antithyroid drug therapy the 20 -minute uptake of ${ }^{132} \mathrm{I}$ by the thyroid gland was measured before and after seven days' treatment with $100 \mu \mathrm{g}$ of T-3 daily (Thomas et al., 1960; Alexander et al., 1966); after thyroidectomy the four-hour uptake of ${ }^{132} \mathrm{I}$ by the thyroid gland was measured (Hobbs et al 1963). In both tests T-3 suppression was regarded as significant when the second uptake was less than $50 \%$ of the first uptake and less than $8 \%$ of the dose administered.

Tests for Autoantibodies. - Antithyroid cytoplasmic antibody was detected by an indirect immunofluoresence technique on cryostat sections of hyperplastic human thyroid gland, and the results were recorded as negative, weak positive, and strong 
positive, depending on the intensity of the fluorescence (Beck, 1971). Antithyroglobulin antibody was detected by the formalinized tanned red cell agglutination test (Fulthorpe et al., 1961); sera with titres of $1 / 250$ and $1 / 2,500$ were considered as weak positives and those $>1 / 2,500$ as strong positives.

Anti-gastric-parietal-cell antibody was detected by an indirect immunofluorescence test on cryostat sections of normal human gastric mucosa (Beck, 1971).

\section{PATIENTS WITH GRAVES'S DISEASE}

All patients in this study had been treated for Graves's disease with hyperthyroidism. The diagnosis was based on a clinical examination (Crooks et al., 1959, 1960), measurement of serum P.B. ${ }^{127}$ I (AutoAnalyser Methodology N-56), and free thyroxine index (Clark and Horn, 1965). In most cases scintiscanning, measurement of uptake by the thyroid gland of ${ }^{131} \mathrm{I}$ at four hours and of P.B. ${ }^{131}$ I at 48 hours, and suppression of the four-hour uptake of ${ }^{132} \mathrm{I}$ by T-3 was carried out. Particular care was taken to exclude all patients who might have single or multiple autonomous nodules.

Three groups of unselected patients were studied.

Group A, 53 Untreated Hyperthyroid Patients.-L.A.T.S. was assayed in all patients before treatment; thyroidal suppressibility was measured in 31 of them immediately before subtotal thyroidectomy and also during a prospective follow-up study between 6 and 17 months later.

Group B, 96 Untreated Hyperthyroid Patients. - Thyroid autoantibodies were measured in these patients who included the 53 patients in group A.

Group C, 141 Postthyroidectomy Patients.-These were taken from a retrospective follow-up study. Thyroid autoantibodies were measured in all patients; serum from 102 (6 recurrent hyperthyroid 55 euthyroid, 41 hypothyroid) was assayed for L.A.T.S. and thyroidal suppressibility was measured in 36 of the euthyroid group.

The age and sex distribution of the patients in groups B and C were similar.

Two groups of selected patients were also studied.

Group D, 19 Patients with Recurrent Hyperthyroidism.-These comprised 6 from the retrospective study (group C) and 13 additional patients, in all of whom thyroid autoantibodies and L.A.T.S. were estimated. Five of these patients had undergone a second thyroidectomy for recurrent hyperthyroidism. Assays of serum and concentrated IgG from 11 of these patients were compared with similar observations on 11 of the patients in group $\mathrm{E}$ who were matched exactly for age and time after operation.

Group E, 14 Euthyroid Postthyroidectomy Patients.-These were from the retrospective study (group $\mathrm{C}$ ); these patients acted as controls in the IgG concentration experiments.

\section{Results}

ASSAY OF L.A.T.S.

Incidence of L.A.T.S. Responses in Patient Surveys.-A positive L.A.T.S. response was found in $5(9.4 \%)$ of the 53 untreated hyperthyroid patients (group A) and in $2(1.9 \%)$ of the 102 unselected postthyroidectomy patients (group C) -1 out of 6 with recurrent thyrotoxicosis and 1 out of 96 without recurrence. The prevalence of positive assays in the untreated hyperthyroid patients was significantly higher than that in the whole group of 102 postthyroidectomy patients $(P=0.039)$. Three $(15.7 \%)$ of the 19 patients with recurrent hyperthyroidism (group D) showed a positive L.A.T.S. response; the prevalence of this abnormality did not differ statistically from that in untreated hyperthyroid patients $(P=0 \cdot 23)$ (Table II).
TABLE II-Prevalence of L.A.T.S. Responses in Patients with Graves's Disease

\begin{tabular}{|c|c|c|c|c|}
\hline \multirow[t]{2}{*}{ Group } & \multirow{2}{*}{\multicolumn{2}{|c|}{ Clinical State of Patients }} & \multicolumn{2}{|c|}{$\begin{array}{l}\text { No. (\%) of Patients in } \\
\text { whom L.A.T.S. Response was }\end{array}$} \\
\hline & & & Positive & Negative \\
\hline $\begin{array}{l}\text { A } \\
\mathbf{D}\end{array}$ & $\begin{array}{l}\text { Untreated hyperthyroid ... } \\
\text { Unselected postthyroidectomy } \\
\text { Recurrent hyperthyroid .. }\end{array}$ & $\begin{array}{l}\cdots \\
\cdots\end{array}$ & $\begin{array}{l}5(9 \cdot 4) \\
2(1 \cdot 9) \\
3(15 \cdot 7)\end{array}$ & $\begin{array}{r}48(90 \cdot 6) \\
100(98 \cdot 1) \\
16(84 \cdot 3)\end{array}$ \\
\hline
\end{tabular}

L.A.T.S. Responses in Fractionation and Concentration Studies.-The whole serum of 11 patients from group D with recurrent hyperthyroidism and 11 euthyroid controls from group E, matched for age and time after operation, showed one L.A.T.S. response in those with recurrence and none in the euthyroid control group. When the concentrated IgG fractions of these sera were assayed, $5(45.5 \%)$ L.A.T.S. responses were found in the recurrent hyperthyroid patients, including the sample positive in unfractionated serum. None of the five patients who had had two operations was positive with whole serum, but two gave positive L.A.T.S. responses with IgG fraction. The IgG fractions of the sera of the 11 euthyroid patients were all negative in the L.A.T.S. assay (Fig. 1).

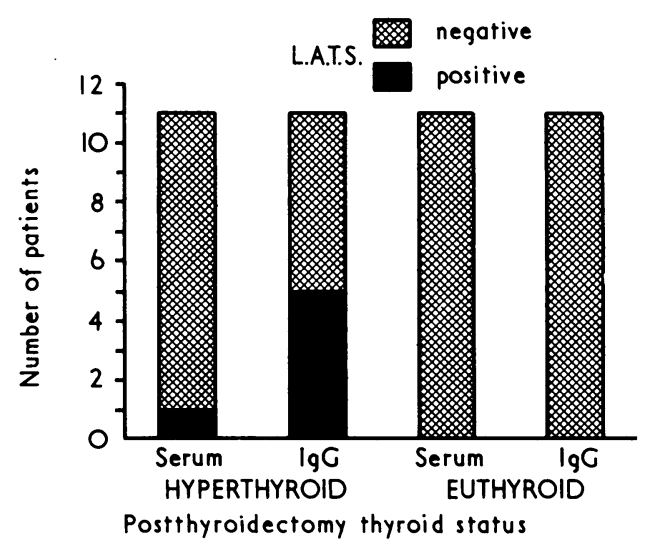

FIG. 1-L.A.T.S. responses in whole serum and IgG fractions of 11 hyperthyroid and 11 euthyroid postthyroidectomy patients matched for age and time after operation.

\section{T-3 SUPPRESSION TESTS}

These tests were carried out during a prospective study of group A hyperthyroid patients who were prepared for subtotal thyroidectomy with conventional doses of antithyroid drugs. Immediately before operation $7(23.3 \%)$ out of 30 patiants showed significant suppression, whereas between 6 and 17 months after operation $22(70.7 \%)$ out of 31 patients showed significant suppression $\left(\chi^{2}=12.03, P<0.001\right)$. In this postthyroidectomy group five patients were hypothyroid, and two of them did not suppress. In 17 patients who were tested both before and after operation five (29\%) suppressed before operation; after operation an additional seven patients suppressed, giving a total of $12(71 \%)\left(\chi^{2}=4.2, P<0.05\right)$. In the retrospective study (group $C$ ) of patients treated by subtotal thyroidectomy between 2 and 21 years previously (mean 9.4 years), $30(82.7 \%)$ out of 36 euthyroid patients tested showed complete suppression. None of the 19 with recurrent hyperthyroidism (group D) suppressed.

\section{AUTOANTIBODIES}

Antithyroid Cytoplasmic Antibodies. - The prevalence of positive antithyroid cytoplasmic antibody tests was $48.4 \%$ in 136 euthyroid or hypothyroid postthyroidectomy patients from 


\begin{tabular}{|c|c|c|c|c|c|c|c|c|c|c|}
\hline \multirow{3}{*}{ Clinical State of Patients } & \multirow{3}{*}{$\begin{array}{l}\text { No. of } \\
\text { Patients }\end{array}$} & \multicolumn{9}{|c|}{ No. of Positive Tests (\%) } \\
\hline & & \multicolumn{3}{|c|}{$\begin{array}{l}\text { Antithyroid Cytoplasmic } \\
\text { Antibody }\end{array}$} & \multicolumn{3}{|c|}{ Antithyroglobulin Antibody } & \multicolumn{3}{|c|}{$\begin{array}{l}\text { Anti-gastric-parietal-cell } \\
\text { Antibody }\end{array}$} \\
\hline & & Total & Weak & Strong & Total & Weak & Strong & Total & Weak & Strong \\
\hline 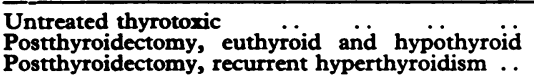 & $\begin{array}{r}96 \\
136 \\
19\end{array}$ & $\begin{array}{l}58(60 \cdot 4) \\
66(48 \cdot 4) \\
15(78 \cdot 9)\end{array}$ & $\begin{array}{r}20(20 \cdot 8) \\
31(22 \cdot 7) \\
9(47 \cdot 3)\end{array}$ & $\begin{array}{l}38(39 \cdot 8) \\
35(25 \cdot 7) \\
6(31 \cdot 6)\end{array}$ & $\begin{array}{r}18(18 \cdot 8) \\
18(13 \cdot 2) \\
8(42 \cdot 1)\end{array}$ & $\begin{array}{r}15(15 \cdot 6) \\
17(12 \cdot 5) \\
7(36 \cdot 8)\end{array}$ & $\begin{array}{l}3(3 \cdot 1) \\
1(0.7) \\
1(5 \cdot 3)\end{array}$ & $\begin{array}{l}19(19 \cdot 8) \\
25(18 \cdot 4)\end{array}$ & $\begin{array}{l}5(5 \cdot 2) \\
8(5 \cdot 8)\end{array}$ & $\begin{array}{l}14(14 \cdot 6) \\
17(12 \cdot 5)\end{array}$ \\
\hline
\end{tabular}

group $C$ and $60.4 \%$ in the series of 96 untreated thyrotoxic patients with similar age distribution $\left(\chi^{2}=2.74, P>0.05\right)$; however, the proportion of strongly positive tests was significantly lower in the postthyroidectomy patients $\left(\chi^{2}=4.38\right.$, $P<0.05)$. The incidence of positive antithyroid cytoplasmic antibody tests was significantly higher in 19 patients (group D) with recurrent hyperthyroidism $(78.9 \%)$ than in the postthyroidectomy patients who were euthyroid or hypothyroid $\left(\chi^{2}=5.02, P<0.05\right)$ (Table III).

Antithyroglobulin Antibody.-These tests were positive in $13.2 \%$ of the 136 postthyroidectomy patients and in $18.8 \%$ of the 96 untreated thyrotoxic patients $\left(\chi^{2}=0.09, P>0.05\right)$; the difference in the proportion of weakly and strongly positive tests did not reach significance at the 5\% level.

Anti-gastric-parietal-cell Antibody.-The prevalence of this antibody was similar in the untreated thyrotoxic $(19.8 \%)$ and the postthyroidectomy $(18 \cdot 4 \%$ ) patients (Table III).

\section{Discussion}

It has been generally accepted that subtotal thyroidectomy relieves the hyperthyroidism of Graves's disease by reducing the capacity of the gland to synthesize thyroxine. However, even after radical subtotal thyroidectomy an appreciable number of patients develop recurrent hyperthyroidism; in a recent followup study in North-east Scotland (Hedley et al., 1970a) the incidence of hypothyroidism was $35 \%$, but, nevertheless, over a 21-year period $6 \%$ of the patients developed recurrent hyperthyroidism. Moreover, in a recent Glasgow series (McLarty et al., 1969) comprising 90 patients with recurrent thyrotoxicosis a second recurrence was found in nine who had been treated by two operations. In the present study a second recurrence was noted in five out of six patients who had had two operations for recurrent hyperthyroidism. These findings suggest that the patients who developed recurrent hyperthyroidism may have responded to operation in a fundamentally different way from the rest.

In interpreting the results of our investigations we have assumed that the thyroid function of patients with a normal T-3 suppression test is controlled by pituitary thyrotropin and conversely that failure to suppress indicates the presence of an extrapituitary stimulator, probably L.A.T.S.

The incidence of L.A.T.S. responses in serum of patients with recurrent hyperthyroidism after subtotal thyroidectomy is more than twice that found in an unselected group of patients with untreated hyperthyroidism. This finding supports the concept that L.A.T.S. is an important aetiological factor in the pathogenesis of recurrent hyperthyroidism, though it does not indicate whether this is persistent or renewed production of L.A.T.S. after subtotal thyroidectomy. However, this study has also shown that subtotal thyroidectomy leads to normal thyroidal suppressibility in over $70 \%$ of patients in the early postoperative period, which is more than twice the number who suppressed during the preparatory antithyroid drug therapy. A retrospective study confirmed that the failure to suppress persists in $20 \%$ of patients, up to 20 years after operation in some cases.
Other studies have reported that between 60 and $100 \%$ of surgically treated patients revert to a normal suppression pattern (Werner, 1956; Eckert et al., 1960; Henneman and Bussemaker, 1969), but the time relationship of this change to the operation had not been defined. The numbers suppressing after radioiodine therapy seem to be much smaller and do not exceed $37 \%$ over similar follow-up periods (Werner, 1956; Eckert et al., 1960). Furthermore, there is no evidence that conventional doses of ${ }^{131}$ I lead to a decrease in L.A.T.S. levels (Pinchera et al., 1969), and even thyroid ablation does not always influence L.A.T.S. levels in patients with high titres before treatment (Volpe et al., 1969; Hedley and Ross, 1971). The finding that $23 \%$ of patients suppressed before operation may be a consequence of antithyroid drug therapy. The extent to which antithyroid drugs may permanently suppress the extrapituitary stimulus has not yet been clearly defined, but it is unlikely that they are the cause, in this study, of the pronounced increase in the numbers of patients who reverted to a normal suppression pattern after operation. Spontaneous remission of the disease process may be responsible for some cases of reversion to normal suppression within the first year after operation, but in view of the disparity between radioiodine and surgically treated patients it is unlikely to be an important factor.

The study has shown that after operation there is a similar but less dramatic reduction in the levels of the two other thyroid autoantibodies; however, subtotal thyroidectomy did not affect the incidence of anti-gastric-parietal-cell antibody. This suggests that operative treatment has had a discriminating effect on thyroid autoimmunity in Graves's disease. It is noteworthy that in the postthyroidectomy patients the antithyroid cytoplasmic antibody is more frequent in patients with a recurrence than in those who were euthyroid or hypothyroid. These observations suggest that there is a parallelism between L.A.T.S. and other thyroid autoantibodies.

\section{IMMUNOLOGICAL CHANGES}

The immediate effect of subtotal thyroidectomy is a reduction in the capacity of the gland to synthesize thyroid hormone, but there is evidence that it also influences the basic process in Graves's disease. The reversion to normal thyroidal suppression and the apparent disappearance of L.A.T.S. in most patients indicate a remarkable change in the autoimmune status, not seen after radioiodine or antithyroid drug treatment. It has been shown previously that small amounts of thyroglobulin are released into the thyroid lymph under physiological conditions, and that this is greatly increased by manipulation of, or surgical trauma to, the gland (Lerman, 1940; Hjort, 1961; Daniel et al., 1967). It is therefore probable that, during and immediately after subtotal thyroidectomy, there is a sudden release of thyroid epithelial cell components and colloid into the blood and lymphatic circulations. It is possible that the sudden massive release of antigens may have immunological consequences; these will be determined by the relative quantities of different antigens released, their relative immunogenicity, and the reaction of the immunological system towards them. 
We consider that it is improbable that these patients have changed production from L.A.T.S. which is known to be an IgG, to a "blocking" antibody of a different Ig class but of the same specificity, loosely analogous to "desensitization"treatment for reaginic disease. This is unlikely, since production of some IgG antibody would be expected to continue, though it must be admitted that this possibility cannot be excluded because the methods for the detection of L.A.T.S. are insensitive. At the present time it is simpler to presume that, after subtotal thyroidectomy, these patients cease production of antibody with the physiological action of L.A.T.S., and in this respect most patients seem to revert from autoimmunity to physiological immunity. This apparent permanent remission amounts to a therapy-induced "cure" of an autoimmune reaction that is without precedent in man. It could be explained by a reacquisition of normal immunological tolerance or by development of secondarily induced immunological paralysis-though the underlying mechanism for these two possibilities may be different, the clinical effects would be similar.

\section{TWO GROUPS}

After subtotal thyroidectomy the patients seem to fall into two groups (Fig. 2): a larger group who reacquire normal thyroidal suppressibility and a smaller group who remain non-suppress-

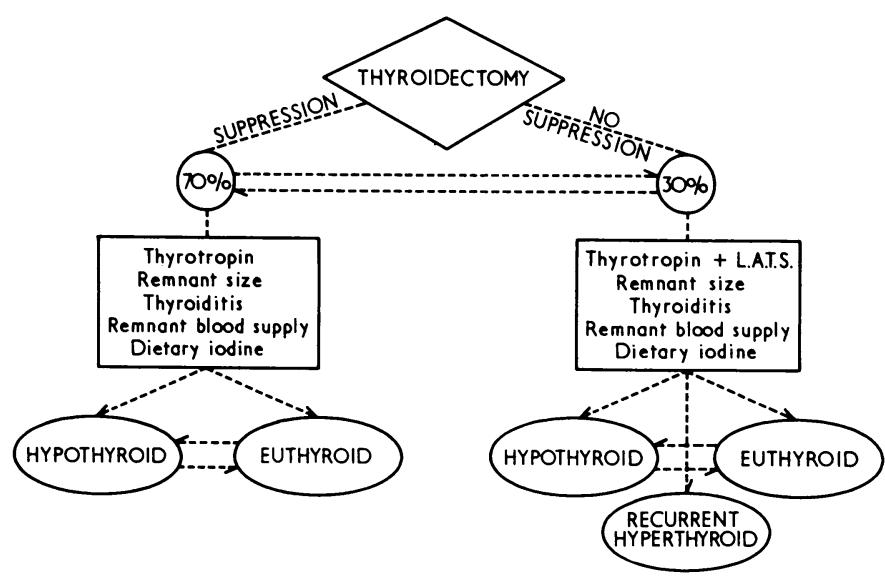

FIG. 2-Diagrammatic representation of factors which may determine the effect of subtotal thyroidectomy in patients with thyrotoxic Graves's disease.

ible. The postoperative thyroid status of patients in each group will be determined by a number of variable factors, such as stimulation of the gland by pituitary thyrotropin (Hedley et al., 1971) and L.A.T.S., the size of the remnant, the presence and extent of thyroiditis, the blood supply of the remnant, and dietary iodine levels. Recurrent hyperthyroidism will occur only in the smaller unsuppressed group, which we have shown to be limited to a maximum of 20 to $30 \%$. Recurrences are probably prevented in most of the patients at risk by radical resection of tissue and/or progressive damage by thyroiditis. Thus attempts to reduce the incidence of postoperative hypothyroidism by increasing the size of the remnant left at operation will probably result in an increased incidence of recurrent hyperthyroidism in the unsuppressed group.

At present it is not possible to predict before operation whether a patient will suppress or fail to suppress after subtotal thyroidectomy. When this can be done, and if subtotal thyroidectomy remains a standard method of treating thyrotoxicosis, it will become possible to rationalize therapy; the remnants would be larger in the postoperative suppressors to reduce the incidence of hypothyroidism and smaller in the non-suppressors, a greater proportion of whom would develop recurrent thyrotoxicosis if a larger remnant was left.

We are grateful to Dr. M. I. Chesters and Mr. J. A. Hetherington for help and advice in the isotope studies, and to Dr. G. Hems for help with the statistics.

One of us (I.P.R.) was supported by a grant from the Scottish Hospitals Endowment Research Trust and the study was also supported in part by the Medical Research Council.

Requests for reprints should be addressed to Dr. A. J. Hedley, Therapeutics Unit, Maryfield Hospital, Dundee.

\section{References}

Albert-Recht, F., and Stewart, C. P. (1961). In Eighth Colloquium on Proteins in Biological Fluids, ed. H. Peeters, p. 50 . Amsterdam, Elserier.

Alexander, W. D., Harden, R. McG., and Shimmins, J. (1966). Lancet, 2, 1041 .

Baumstark, J. S., Laffin, R. J., and Bardawil, W. A. (1964). Archives of Biochemistry and Biophysics, 108, 514

Beck, J. S. (1971). Association of Clinical Pathologists, London, Broadsheet No. 69.

Carneiro, L., Dorrington, K. J., and Munro, D. S. (1966). Lancet, 2, 878. Cattell, R. B. (1949). Fournal of Clinical Endocrinology and Metabolism, 9, 999. Clark, F., and Horn, D. B. (1965). Fournal of Clinical Endocrinology and Metabolism, 25, 39 .

Clute, H. M., and Veall, J. R. (1932). Fournal of the American Medical Association, 99, 642.

Crile, G., and McCullagh, E. P. (1951). Annals of Surgery, 134, 18.

Crooks, J., Murray, I. P. C., and Wayne, E. J. (1959). Quarterly fournal of Medicine, 28, 211.

Crooks, J., Wayne, E. J., and Robb, R. A. (1960). Lancet, 1, 397.

Daniel, P. M., Pratt, O. E., Roitt, I. M., and Torrigiani, G. (1967). Immunology, 12, 489.

Eckert, H., Green, M., Kilpatrick, R., and Wilson, G. M. (1960). Clinical Science, 20, 87.

Enzel, A. (1932). Acta Medica Scandinavica, 79, 125.

Fahey, J. L., and McKelvey, E. M. (1965). Fournal of Immunology, 94, 84 Fulthorpe, A. J., Roitt, I. M., Doniach, D., and Couchman, K. G. (1961). fournal of Clinical Pathology, 14, 654 .

Gilette, N. N. (1937). Western fournal of Surgery and Obstetrics, 45, 504.

Hayles, A. B., Kennedy, R. L. J., Beahrs, O. H., and Woolner, L. B. (1959). fournal of Clinical Endocrinology and Metabolism, 19, 138.

Hedley, A. J., Flemming, C. J., Chesters, M. I., Michie, W., and Crooks, J. (1970a). British Medical fournal, 1, 519.

Hedley, A. J., Ross, I. P., and Crooks, J. (1970b). Lancet, 2, 468.

Hedley, A. J., Hall, R., Amos, J., Michie, W., and Crooks, J. (1971). Lancet, 1,455 .

Hedley, A. J., and Ross, I. P. (1971). Unpublished.

Henneman, G., and Bussemaker, J. K. (1969). Lancet, 1, 588.

Hjort, T. (1961). Lancet, 1, 1262.

Hobbs, J. R., Bayliss, R. I. S., and MacLagan, N. F. (1963). Lancet, 1, 8.

Jordan, S. M. (1925). Archives of Surgery, 11, 1 .

Lerman, J. (1940). Fournal of Clinical Investigation, 19, 555.

McKenzie, J. M. (1958). Endocrinology, 63, 372.

McLarty, D. G., Alexander, W. D., Harden, R. McG., and Clark, D. H. (1969). British Medical fournal, 3, 200.

Perper, R. J., Ekimoto, J. T., Cochrum, K. C., Ramsey, N., and Najarian, J. S. (1967). Proceedings of the Society of Experimental Biology and Medicine, 125, 575.

Pinchera, A., et al. (1969). Fournal of Clinical Endocrinology and Metabolism, 29, 231 .

Rasmussen, H. (1937). Acta Medica Scandinavica, 91, 69.

Rasmussen, H. (1937). Acta Medica Scandinavica, 91,
Riddell, V. (1962). British fournal of Surgery, 49, 65.

Riddell, V. (1962). British Fournal of Surgery, 49, 65.
Roy, A. D., Allan, J., and Harden, R. McG. (1967). Lancet, 2, 684.

Roy, A. D., Allan, J., and Harden, R. McG. (1967). Lancet, 2, 684.

Scheidegger, J. J. (1955). International Archives of Allergy, 7, 103. Endocrinology and Metabolism, 20, 1601 .

Thomson, W. O., Morris, A. E., and Thompson, P. K. (1930). Archives of Internal Medicine, 46, 946.

Volpe, R., Desbarats-Schonbaum, M. L., Schonbaum, E., Row, V. V., and Ezrin, C. (1969). American fournal of Medicine, 46, 217.

Werner, S. C. (1956). Fournal of Clinical Investigation, 35, 57. 